\title{
When Going Green Backfires: How Firm Intentions Shape the Evaluation of Socially Beneficial Product Enhancements
}

\author{
GEORGE E. NEWMAN \\ MARGARITA GORLIN \\ RAVI DHAR
}

\begin{abstract}
Many companies offer products with social benefits that are orthogonal to performance (e.g., green products). The present studies demonstrate that information about a company's intentions in designing the product plays an import role in consumers' evaluations. In particular, consumers are less likely to purchase a green product when they perceive that the company intentionally made the product better for the environment compared to when the same environmental benefit occurred as an unintended side effect. This result is explained by consumers' lay theories about resource allocation: intended (vs. unintended) green enhancements lead consumers to assume that the company diverted resources away from product quality, which in turn drives a reduction in purchase interest. The present studies also identify an important boundary condition based on the type of enhancement and show that the basic intended (vs. unintended) effect generalizes to other types of perceived tradeoffs, such as healthfulness and taste.
\end{abstract}

$\mathrm{O}$ ne of the most common ways for a company to increase the desirability of a product is through the addition of new product features. Typically, such product enhancements are performance related (e.g., faster processor, better camera resolution). Increasingly, however, many companies offer socially beneficial product enhancements that are orthogonal to the product's performance, such as benefits to the environment or benefits to the workers who produced it (e.g., fair trade). While previous research has examined

George E. Newman is assistant professor of organizational behavior at the Yale School of Management, 165 Whitney Ave, New Haven, CT 06520 (george.newman@yale.edu). Margarita Gorlin is a PhD candidate at the Yale School of Management, 165 Whitney Ave, New Haven, CT 06520 (margarita.gorlin@yale.edu). Ravi Dhar is the George Rogers Clark Professor of Management and Marketing at the Yale School of Management, 165 Whitney Ave, New Haven, CT 06520 (ravi.dhar@yale.edu). Please address correspondence to George Newman. The authors would like to thank Jennifer Savary for her helpful comments on an earlier draft. They would also like to thank Jon Cummings and Holly Hegener, the F. K. Weyerhaeuser Memorial Fund, the Yale Center for Business and the Environment, and Sears Canada for their financial support of the research.

Ann McGill served as editor and Darren W. Dahl served as associate editor for this article.

Electronically published August 15, 2014 how performance-related enhancements are evaluated (Mukherjee and Hoyer 2001; Nowlis and Simonson 1996; Thompson, Hamilton, and Rust 2005), less is known about how these other types of nonperformance, socially beneficial enhancements are evaluated.

The present studies focus on green product enhancements and, specifically, how the communication of environmental benefits as intended or unintended affects consumers' purchase decisions. Imagine, for example, a firm that has developed a new product that is better for the environment. One option is to communicate that the green benefit was intended: the firm may highlight that it is concerned about the sustainability of its products and as a result, it developed a new product that is better for the environment. Alternatively, however, the firm may communicate that the green benefit was actually an unintended side effect; it may advertise that it was trying to develop a new product that satisfied some other goal and that the environmental benefit was merely a by-product of those efforts.

There are a number of real-world cases that reflect these different communication strategies. For example, Method, a certified B corporation that manufactures household cleaning and personal care products, advertises that "we keep the planet in mind with every bottle we design." Or, when BMW launched the "Efficient Dynamics" campaign for more environmentally sustainable automobiles, the company stated 
that their goal was "to increase both efficiency and performance at once." Conversely, when Anheuser Busch released the new aluminum bottles for their top-selling beers in 2005, the campaign highlighted how the new bottle looked different from others in the marketplace and considerably downplayed the significant environmental benefit of using aluminum. Similarly, when Apple Computers rolled out designs for its new unibody laptops, the company highlighted that its innovative use of aluminum was central to the improved performance and durability of the laptops and that the green benefits of using aluminum were a by-product of those efforts.

All else being equal, it would seem that intending to make a product better should be preferred to unintentionally doing so. However, the present studies demonstrate the opposite effect. Here we show that when a company manufactures a product that is better for the environment, consumers are less likely to purchase it if the green benefit is perceived as intended than when the same environmental benefit is perceived as an unintended side effect. Thus, we demonstrate a counterintuitive effect of intended product enhancements, such that intending to improve a product may actually lead to a decrease in consumer interest.

We show that this effect results from consumers' lay theories about the relationship between a firm's intentions and its allocation of resources. Specifically, when a company intends to make a product better for the environment, consumers assume that in order to make a product more environmentally friendly, the company diverted resources away from product quality. In other words, intended (vs. unintended) enhancements lead consumers to infer that the company devoted greater resources to the green benefit and invested fewer resources in quality. In turn, this reduction in perceived quality drives a reduction in purchase interest.

The present studies demonstrate the link between these factors (i.e., firm intentions, lay theories of resource allocation, perceptions of product quality, and purchase intent) while also ruling out several alternative explanations for this effect (e.g., signaling that the firm cares less about quality). Additionally, we identify an important boundary condition of this effect and also show that the basic intended (vs. unintended) effect generalizes to other types of perceived trade-offs, such as the relationship between the healthfulness of a product and its taste.

This work highlights the centrality of firm intentions to consumer perceptions - while beliefs about intentionality are central to many aspects of psychology, to date, little is known about how intentions influence consumers' purchase decisions. Moreover, given that the "greening" of products is a fast-growing industry, our results may hold important practical implications for devising communication strategies about the introduction of green products to the marketplace.

\section{THEORETICAL BACKGROUND}

\section{Reasoning about Intentions}

A large literature within psychology and experimental philosophy has examined how lay theories about intention- ality inform people's judgments. For example, a well-established finding in the moral psychology literature is that intended harms are rated as less moral than equivalent unintended harms (Cushman and Mele 2008; Pizarro, Uhlmann and Salovey 2003; Young et al. 2006). People may also use the moral valence of an action to make determinations about intentionality. For example, Knobe and his colleagues (Knobe 2003a, 2003b; Leslie, Knobe, and Cohen 2006) demonstrated that people's intuitions regarding whether a behavior was performed intentionally are influenced by their beliefs about whether the behavior itself is right or wrong.

While past research has explored how intentionality shapes morally relevant judgments, less research has examined the role of firm intentions in consumer decision making. One natural area to examine this question is in the domain of environmentally beneficial (or "green") products. In the past few decades, consumers have become increasingly concerned about the moral responsibility to preserve the environment for future generations (Caruana 2007; Irwin and Baron 2001). In turn, this increased concern has led to remarkable growth in the market for environmentally friendly products (e.g., Hunt and Dorfman 2009).

Here we test the prediction that information about a firm's intentions may affect evaluations of green products in a potentially counterintuitive manner. Namely, we hypothesize that green products may actually be evaluated worse if a firm communicates that the green benefit was intended than when it communicates that the same environmental benefit occurred as an unintended side effect. This prediction draws from both the existing literature on intentionality as well as from research on how consumers evaluate trade-offs among product attributes.

\section{Intentions, Resource Allocation, and Zero-Sum}

Past research on intentionality suggests an important link between intentions and perceived effort (Heider 1958). For example, if we cannot observe a person's actions, knowledge about intentions can inform our beliefs about the extent to which the person was responsible for a particular outcome (Lombrozo 2010) and his or her degree of motivation (Dik and Aarts 2007; Kruger et al. 2004). And within consumer behavior, consumers may associate perceived effort with the motivations of the firm (Morales 2005).

Applied to the present research, we hypothesize that when a company is described as intentionally making a product better for the environment, consumers will infer that the firm devoted greater resources toward "greening the product," compared with when the same outcome was achieved unintentionally (e.g., when the green benefit occurred as a by-product of some other effort). Therefore, we propose that intentionality in this case is naturally interpreted as making reference to the firm's allocation of resources.

This inference about resource allocation is important because past research on the zero-sum heuristic (Chernev 2007; Chernev and Carpenter 2001) suggests that consumers have a lay theory that firm resources are zero-sum-in other words, that superiority on one product dimension is com- 
pensated by inferiority on other dimensions (Chernev 2007; Chernev and Carpenter 2001). For example, a toothpaste that specializes in its cavity-fighting ability may be inferred to be inferior on tartar control (Chernev 2007). In the domain of green products, this suggests that consumers may infer that devoting more resources to the green enhancement necessarily implies that the firm invested fewer resources in other quality dimensions.

Note that, in actuality, a company could intend to enhance a particular dimension (e.g., a product's environmental benefits) without necessarily sacrificing quality on other dimensions or changing the product's performance along other attributes. Therefore, we suggest that inferences about quality in this context are drawing from consumers' lay theories rather than from their actual knowledge about the particular product category.

Because inferences about product quality are importantly related to purchase intentions, we predict that these inferences about firm resources will have downstream consequences for purchase intent, such that consumers will be less likely to purchase products with intended green enhancements than products with unintended green enhancements. This is perhaps the most novel and counterintuitive prediction, since (a) past research on compensatory inferences has tended to look at perceptions of quality but not at the subsequent effects on purchase decisions, and $(b)$ we are proposing that intending to enhance a product (i.e., make it more appealing) may actually make consumers less likely to purchase it. This prediction about purchase intent is potentially quite relevant to practitioners when considering that, from the perspective of corporate social responsibility, if a company wants to be seen as helping the environment then it is critical that its actions be seen as intentional (Brown and Dacin 1997; Creyer 1997; Sen and Bhattacharya 2001).

In sum, combining the literatures on intentionality and the zero-sum heuristic, we suggest that consumers should be less likely to purchase products with intended green enhancements than products with unintended green enhancements and that this effect should be mediated by consumers' inferences about how the company allocated its resources. Stated formally, this proposal makes the following three predictions:

H1: Consumers will infer that the firm diverted more resources away from product quality when the green enhancement is intended (vs. unintended).

H2: Consumers will infer lower product quality when the green enhancement is intended (vs. unintended).

H3: Consumers will be less likely to purchase the product when the green enhancement is intended (vs. unintended).

\section{OVERVIEW OF STUDIES}

To test these hypotheses, we conducted a series of four experiments. Experiment 1 provides support for the three central hypotheses regarding resource allocation (hypothesis 1), quality inferences (hypothesis 2), and purchase intent (hypothesis 3). In addition, this study tests the hypothesized mediation model that intended (vs. unintended) green enhancements lead people to infer that the firm diverted more resources away from quality, which in turn leads to decreased quality ratings and, ultimately, lower purchase intent. To assess what consumers infer in the absence of information about intentions, this study also included a control condition in which no information about intentions was provided.

Experiments $2 \mathrm{a}$ and $2 \mathrm{~b}$ lend further support to the proposed mechanism by replicating the impact of firm intentions on perceptions of resource allocation, quality, and purchase intent and by replicating the hypothesized mediation model. These studies also addressed two alternative explanations for the effect, which were related to the possibility that the intended (vs. unintended) framings signaled something about the firm's specialization or lack of focus on quality. (We discuss these alternatives in further detail along with each of the studies.)

Experiment 3 tested an important boundary condition. Previous research has identified a positive halo effect stemming from socially beneficial product attributes (Blair and Chernev 2014; Schuldt, Muller, and Schwarz 2012). Our theory about resource allocation and zero-sum predicts that one key moderator of the effect of intended (vs. unintended) enhancements on purchase intent is whether the social benefit is inherent to the product. This study shows that the proposed negative effect of intended (vs. unintended) enhancements holds only if the enhancement is inherent to the product. When the benefit is separate from the product (e.g., fair trade), consumers should no longer infer that the company diverted resources away from product quality and therefore should evaluate the product more favorably when the benefit is intended (vs. unintended).

Finally, experiment 4 tests the generality of the intended (vs. unintended) effect. This study builds on previous research which has identified a tasty $=$ unhealthy lay theory regarding food products (Raghunathan, Naylor, and Hoyer 2006) and tests whether intentionally healthier products are rated as less tasty than products that are healthier as the result of an unintended side effect.

\section{EXPERIMENT 1: INTENDED VERSUS UNINTENDED ENHANCEMENTS}

The first study tested our central hypothesis that consumers are less likely to purchase a green product when the environmental benefit is intended versus unintended. In addition, we hypothesized that inferences about resource allocation should explain this difference. Thus, we predicted a specific serial mediation model whereby information that a green enhancement was intended (vs. unintended) should lead participants to infer that the firm diverted more resources away from product quality. In turn, this belief about resource allocation should lead to lower quality ratings and 
FIGURE 1

MEAN RATINGS OF PURCHASE INTENT, PRODUCT QUALITY, AND RESOURCE ALLOCATION (EXPERIMENT 1)

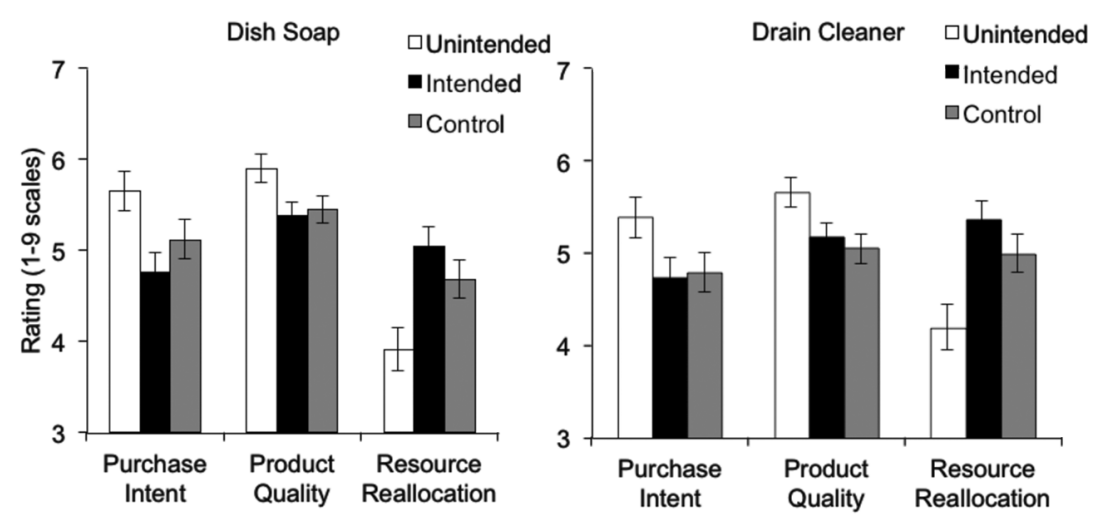

ultimately, lower purchase intent (i.e., intentions $\rightarrow$ resources $\rightarrow$ quality $\rightarrow$ purchase intent).

To examine what consumers infer in the absence of information about firm intentions, this study included a control condition in which no information about intentions was provided. Consistent with previous research demonstrating that the default is for consumers to assume that any product enhancement was described was intended (Chernev 2007), we predicted that the control condition should follow the same pattern as the condition in which the firm intentionally enhanced the product.

\section{Method}

Three hundred three adult participants were recruited from Amazon's Mechanical Turk $\left(M_{\mathrm{age}}=33.1,52.5 \%\right.$ female $)$ and were randomly assigned to one of three conditions: intended green enhancement, unintended green enhancement, or control. All participants read short descriptions of two new environmentally friendly products (a dish soap and a drain cleaner), which were presented sequentially on different pages. In both cases, the products were described as "significantly better for the environment than competing brands." In the intended condition, participants read that "as initially intended, this new dishwashing soap [drain cleaner] is significantly better for the environment than competing brands," while in the unintended condition, participants read that the green improvement occurred "as an unintended side effect." In the control condition, there was no mention of the firm's intentions (see app. A for all materials used in this study).

For each product, all participants then answered a series of questions that assessed their perceptions of product quality, resource allocation, and purchase intent. Specifically, for each product, participants responded to two items assessing product quality along nongreen dimensions (e.g., How would you rate the cleaning efficacy of this new dishwashing

soap? How would you rate the ability of this new dishwashing soap to remove grease? $1=$ low, $5=$ average, 9 $=$ high). Participants also evaluated the company's perceived use of resources through their agreement with the statement "In order to make the dishwashing soap [drain cleaner] better for the environment, the company took resources away from making this product better in quality" ( $1=$ not at all, $9=$ very much so). Finally, participants indicated their purchase intent on a 9 -point scale $(1=$ definitely would not buy, 9 = definitely would buy).

\section{Results}

Purchase Intent. Results from this study are depicted in figure 1. A one-way ANOVA revealed a significant effect of firm intentions on ratings of purchase intent for both the dish soap, $F(2,300)=4.74, p=.009$ and the drain cleaner, $F(2,300)=2.98, p=.052$. Consistent with our predictions, a planned contrast confirmed that participants expressed higher purchase intent in the unintended condition than the intended and control conditions for both the dish soap $\left(M_{\text {unint }}\right.$ $=5.65, \mathrm{SD}=2.11$ versus $M_{\mathrm{int}}=4.77, \mathrm{SD}=1.95$ and $\left.M_{\text {con }}=5.12, \mathrm{SD}=2.11 ; t(300)=2.83, p=.005\right)$ and the drain cleaner $\left(M_{\text {unint }}=5.39, \mathrm{SD}=2.20\right.$ versus $M_{\mathrm{int}}=$ $4.74, \mathrm{SD}=2.09$ and $M_{\text {con }}=4.79, \mathrm{SD}=2.11 ; t(300)=$ 2.44, $p=.015)$.

Resource Allocation. As predicted, differences in intentionality also had an effect on inferences about the firm's allocation of resources. A one-way ANOVA revealed a significant effect of firm intentions on inferences about resource allocation for both the dish soap, $F(2,300)=7.55, p=$ .001 , and the drain cleaner, $F(2,300)=7.52, p=.001$. A planned contrast confirmed that participants thought that the company had diverted more resources away from product quality in both the intended and control conditions than in the unintended condition for both the dish soap $\left(M_{\text {unint }}=\right.$ 
3.91, $\mathrm{SD}=2.36$ versus $M_{\text {int }}=5.05, \mathrm{SD}=1.99$ and $M_{\text {con }}$ $=4.68, \mathrm{SD}=2.02 ; t(300)=3.68, p<.001)$ and the drain cleaner $\left(M_{\text {unint }}=4.19, \mathrm{SD}=2.52\right.$ versus $M_{\text {int }}=5.36, \mathrm{SD}$ $=2.01$ and $M_{\text {con }}=4.99, \mathrm{SD}=2.05 ; t(300)=3.69, p<$ $.001)$.

Product Quality. The two items related to product quality were highly correlated for both of the products $(r=$ .79 for dish soap and $r=.78$ for drain cleaner) and were averaged to produce one measure of quality for each product. A one-way ANOVA revealed a significant effect of firm intentions on ratings of product quality for both the dish soap, $F(2,300)=3.85, p=.022$, and the drain cleaner, $F(2,300)=4.41, p=.013$. In addition, a planned contrast confirmed that product quality ratings were higher in the unintended condition than the intended and control conditions for both the dish soap $\left(M_{\text {unint }}=5.90, \mathrm{SD}=1.47 \mathrm{vs}\right.$. $M_{\text {int }}=5.38, \mathrm{SD}=1.43$ and $M_{\text {con }}=5.45, \mathrm{SD}=1.40$; $t(300)=2.75, p=.006)$ and the drain cleaner $\left(M_{\text {unint }}=\right.$ $5.66, \mathrm{SD}=1.64$ vs. $M_{\text {int }}=5.17, \mathrm{SD}=1.51$ and $M_{\text {con }}=$ $5.05, \mathrm{SD}=1.53 ; t(300)=2.92, p=.004)$.

Mediation. We then tested the specific predicted pathway (firm intentions $\rightarrow$ resource allocation $\rightarrow$ quality $\rightarrow$ purchase intent) using a serial mediation model. In all previous analyses, results in the intended and control conditions followed the same pattern. Therefore, we dummy coded the three conditions as $1=$ unintended, $0=$ intended, and control. We then entered the measures of resource allocation and product quality as mediators of the effect of firm intentions on purchase intent. Separate mediation analyses were run for each of the products. A bootstrap analysis with 5,000 samples (Preacher and Hayes 2008) indicated that the full serial mediation model using both quality and resource allocation was significant for the dish soap (indirect effect $=$ $.134, \mathrm{SE}=.06,95 \% \mathrm{CI}=.041$ to .282$)$ and the drain cleaner (indirect effect $=.187, \mathrm{SE}=.07,95 \% \mathrm{CI}=.075$ to .361). However, additional analyses indicated that the "reverse" model (intentions $\rightarrow$ quality $\rightarrow$ resources $\rightarrow$ purchase intent) was much weaker for the dish soap (indirect effect $=.014, \mathrm{SE}=.11,95 \% \mathrm{CI}=.002$ to .049$)$ and nonsignificant for the drain cleaner (indirect effect $=.013$, $\mathrm{SE}=.01,95 \% \mathrm{CI}=-.003$ to .046$)$, suggesting that the predicted serial mediation model best explained our data.

We also conducted a second set of regression analyses with only the intended and unintended conditions and observed an identical set of results. The full serial mediation model using both quality and resource allocation was significant for the dish soap (indirect effect $=.11, \mathrm{SE}=.07$, $95 \% \mathrm{CI}=.004$ to .29 ) and the drain cleaner (indirect effect $=.22, \mathrm{SE}=.08,95 \% \mathrm{CI}=.087$ to .424$)$. However, additional analyses indicated that the "reverse" models (intentions $\rightarrow$ quality $\rightarrow$ resources $\rightarrow$ purchase intent) were not significant for the dish soap (indirect effect $=.01, \mathrm{SE}=$ $.01,95 \% \mathrm{CI}=-.0002$ to .053 ) or the drain cleaner (indirect effect $=.01, \mathrm{SE}=.01,95 \% \mathrm{CI}=-.003$ to .059$)$, suggesting that the predicted serial mediation model best explained our data.

\section{Discussion}

These results were consistent with the predictions outlined in the Introduction. Specifically, a difference in firm intentions led consumers to draw different inferences about the firm's allocation of resources. In turn, beliefs about resource allocation changed perceptions of product quality and, ultimately, purchase intent. Moreover, this study established that in the absence of information about firm intentions, consumers appear to infer intentionality-in other words, intended enhancements (and compensatory inferences) appear to be the default assumption.

\section{EXPERIMENT 2: ALTERNATIVE EXPLANATIONS}

Experiments $2 \mathrm{a}$ and $2 \mathrm{~b}$ sought to address two potential alternative explanations for the intended versus unintended enhancement effect. The first is that companies may choose to indirectly signal their best product features, and, hence, any feature that a firm intentionally enhances reflects the firm's strongest attribute. For example, by advertising that a Las Vegas resort is "good for families," a firm may be signaling a lack of gambling options. Therefore, the fact that a company chooses to green its products may signal that its products are of lower quality. Note that the results of the control condition in experiment 1 do not support this proposal, since in that condition the firm's intentions were never mentioned, and yet participants made the same pattern of inferences as in the intended condition. Nevertheless, to test this alternative, experiment $2 \mathrm{a}$ included a fourth care-aboutboth condition in which participants were explicitly told that the firm intended to improve both the product's environmental benefits and its quality (similar to the BMW example in the introduction). Our proposed resource allocation account, however, predicts that this should not be effective, given that consumers should still assume that resources are zero-sum. Therefore, even when the company intends to both green the product and improve quality, consumers should be less likely to purchase the product compared to a case when the same green enhancement occurred unintentionally.

Experiment $2 \mathrm{~b}$ sought to address yet another potential explanation for the effect. In the previous studies the materials explicitly stated that the company was developing a new product. Therefore, in cases where the green enhancement occurred unintentionally, participants might have inferred that if the company was not focused on greening the product, it must have been focused on improving quality. In other words, communicating that the company had developed a new product with an unintended green benefit may lead to the inference that the company had successfully improved both the environmental impact and the quality of the product.

To address this possibility, experiment $2 \mathrm{~b}$ presented a new scenario in which we explicitly stated that the company sought to improve a particular dimension (e.g., the viscosity of a drain cleaner). In cases where the green benefit was 
unintended, participants read that the company intended to improve viscosity, while the green benefit occurred as an unintended side effect. In contrast, when the green benefit was intended, participants read that the company intended to improve both viscosity and the product's environmental impact. If this alternative explanation based on differential focus is correct, when participants are explicitly told that the firm intended to improve the drain cleaner's viscosity, the intended versus unintended green enhancement should have no effect on beliefs about resource allocation and purchase intent. However, if the resource allocation account is correct, then we should obtain the results of the previous study even when participants are explicitly told that the company's primary focus was to improve viscosity. In other words, participants should still infer that the company diverted more resources away from product quality when it was intentionally pursuing both viscosity and green benefits.

\section{Method}

Experiment 2a. Four hundred four adult participants were recruited from Amazon's Mechanical Turk $\left(M_{\text {age }}=\right.$ $27.7,36 \%$ female). Participants were randomly assigned to one of four conditions (intended, unintended, control, and care-about-both) and read a description of a new green product, an all-purpose cleaner. As in experiment 1, participants in the intended condition read that "as initially intended, the cleaner is better for the environment," whereas participants in the unintended enhancement condition read that the green enhancement occurred as "an unintended side effect." The control condition made no mention of intentions. Finally, participants in the care-about-both condition read that the company "intended to create a product that is both good for the environment and is a good household cleaner" (see app. B).

After reading the description about the household cleaner, participants reported the following three items: rating of product quality for the new all-purpose cleaner ("How would you rate the cleaning efficacy of this new all-purpose cleaner?" 1 = low, $5=$ average, $9=$ high), agreement with the resource allocation statement, and purchase intent for the product. The resource allocation and purchase intent measures were the same as in the previous study.

Experiment $2 b$. Five hundred fourteen adult participants $\left(M_{\text {age }}=33,62 \%\right.$ female $)$ were recruited while attending a Fourth of July fireworks display. This survey appeared in a packet containing several other unrelated studies and was the only one examining green products.

Participants were randomly assigned to one of four conditions in a 2 (intention: intended vs. unintended) $\times 2$ (focal attribute: specified vs. unspecified) design. All participants read about a drain cleaning solution with a green enhancement. As in the previous two studies, participants in the two intended conditions read that as "initially intended, the cleaner is better for the environment," whereas participants in the unintended conditions read that the green enhancement occurred as "an unintended side effect." Participants in the unintended + focal attribute specified condition read that the company was trying to develop a formula which would "have better viscosity," whereas those in the intended + focal attribute specified condition read that the firm developed a formula that would "both have better viscosity and be better for the environment." Participants in the "focal attribute unspecified" conditions saw the same prompts as in the previous studies.

After reading the drain cleaner description, participants reported their perception of the product's quality on two items ("How would you rate the ability of this new drain cleaner to break up clogs?" and "How would you rate the ability of this new drain cleaner to prevent future buildup?"; $1=$ low, $5=$ average, $9=$ high), their agreement with the resource allocation statement, and their purchase intent. The resource allocation and purchase intent measures were the same as in the previous two studies (see app. C).

\section{Experiment 2a Results}

Purchase Intent. Results from this study are depicted in figure 2. A one-way ANOVA indicated a significant effect of condition on ratings of purchase intent, $F(3,400)=5.28$, $p=.001$. Contrary to the signaling alternative, purchase intent in the care-about-both condition was significantly lower than in the unintended condition $\left(M_{\mathrm{both}}=5.57, \mathrm{SD}\right.$ $=1.81$ vs. $\left.M_{\text {unint }}=6.22, \mathrm{SD}=1.76\right), t(203)=-2.58, p$ $=.010$ and was not significantly different from the intended and control conditions $\left(M_{\mathrm{int}}=5.22, \mathrm{SD}=2.06, M_{\text {con }}=\right.$ $5.80, \mathrm{SD}=1.63), t(200)=1.29$ and $t(201)=-.94$, respectively, $p>$.1. A planned contrast indicated that participants expressed higher purchase intent in the unintended condition than in the intended, control, or care-about-both conditions, $t(400)=3.28, p=.001$.

Resource Allocation. A one-way ANOVA revealed a significant effect of condition on beliefs about resource allocation, $F(3,400)=13.74, p<.001$. Contrary to the signaling alternative, participants thought that the firm diverted more resources away from product quality in the care-

\section{FIGURE 2}

MEAN RATINGS OF PURCHASE INTENT, PRODUCT QUALITY, AND RESOURCE ALLOCATION (EXPERIMENT 2A)

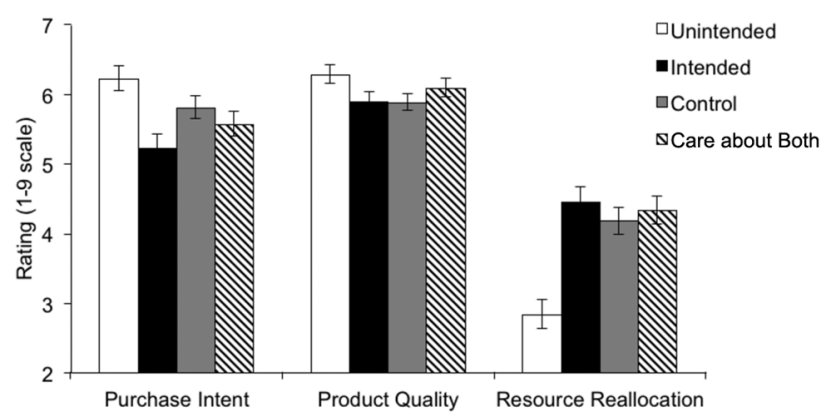


about-both condition than in the unintended condition ( $M_{\text {both }}$ $=4.33, \mathrm{SD}=2.03$ vs. $\left.M_{\text {unint }}=2.84, \mathrm{SD}=2.05\right), t(203)$ $=5.22, p<.001$. In addition, beliefs about resource allocation in the care-about-both condition were not significantly different from the intended and control conditions $\left(M_{\mathrm{int}}=4.45, \mathrm{SD}=2.16, M_{\text {con }}=4.18, \mathrm{SD}=1.88\right), t(200)$ $=.42$ and $t(201)=.55$, respectively, $p>.1$. A planned contrast confirmed that participants thought that the firm diverted more resources away from quality in the intended, control, and care-about-both conditions than in the unintended condition, $t(400)=6.35, p<.001$.

Product Quality. A one-way ANOVA revealed a marginally significant effect of condition on ratings of product quality, $F(3,400)=2.19, p=.088$. Participants rated the product as somewhat lower quality in the care-about-both condition than in the unintended condition $\left(M_{\text {both }}=6.09\right.$, $\mathrm{SD}=1.34$ vs. $\left.M_{\text {unint }}=6.28, \mathrm{SD}=1.32\right)$, though this difference did not reach statistical significance, $t(203)=$ $1.06, p=.29$. However, ratings of product quality in the care-about-both condition did not differ significantly from those in the intended and control conditions $\left(M_{\text {int }}=5.89\right.$, $\left.\mathrm{SD}=1.37, M_{\text {con }}=5.88, \mathrm{SD}=1.17\right), t(200)=1.04$ and $t(201)=1.18$, respectively, $p>.1$. And, a planned contrast confirmed that participants thought that the firm diverted fewer resources away from quality in the unintended condition than in the intended, control, or care-about-both conditions, $t(400)=2.23, p=.026$.

Mediation. To test the proposed mechanism, we entered both perceptions of resource allocation and product quality into a serial mediation model predicting purchase intent (analogous to the previous study). Since results in the intended, control, and care-about-both conditions followed the same pattern in this study, we dummy-coded those three conditions as $1=$ unintended and $0=$ intended, control, and care-about-both. A bootstrap analysis with 5,000 samples (Preacher and Hayes 2008) indicated that the full serial mediation model using both quality and resource allocation was significant (indirect effect $=.095, \mathrm{SE}=.04,95 \% \mathrm{CI}$ $=.027$ to .192). However, additional analyses indicated that the "reverse" model (intentions $\rightarrow$ quality $\rightarrow$ resources $\rightarrow$ purchase intent) was much weaker (indirect effect $=.017$, $\mathrm{SE}=.11,95 \% \mathrm{CI}=.002$ to .053$)$, suggesting that the predicted serial mediation model best explained our data.

\section{Experiment $2 b$ Results}

Purchase Intent. A two-way ANOVA revealed a significant main effect of firm intentions on purchase intent, such that purchase intent was higher when the green improvement was unintended $(M=5.20, \mathrm{SD}=2.20)$ than when it was intended $(M=4.64, \mathrm{SD}=2.03), F(1,505)$ $=8.33, p=.004$. This effect held both when the focal benefit was specified $\left(M_{\text {unint } \mathrm{spec}}=5.34, \mathrm{SD}=2.29\right.$ vs. $\left.M_{\text {int }+ \text { spec }}=4.73, \mathrm{SD}=1.97\right), t(255)=2.25, p=.025$, and when it was unspecified $\left(M_{\text {unint }}=5.04, \mathrm{SD}=2.08 \mathrm{vs}\right.$. $\left.M_{\mathrm{int}}=4.56, \mathrm{SD}=2.09\right), t(250)=1.83, p=.069$. In contrast, there was no effect of focal attribute (whether the focal attribute was specified or unspecified) and no interaction, $p>.21$.

Resource Allocation. A two-way ANOVA revealed a significant main effect of firm intentions on perceptions of resource allocation, such that participants thought that the company diverted more resources away from product quality when the green enhancement was intended $(M=4.57, \mathrm{SD}$ $=2.03)$ than when it was unintended $(M=3.56, \mathrm{SD}=$ 2.24), $F(1,510)=28.12, p<.001$. This effect held both when the focal attribute was specified $\left(M_{\text {unint }+ \text { spec }}=3.35\right.$, $\mathrm{SD}=2.22$ vs. $\left.M_{\text {int }+ \text { spec }}=4.40, \mathrm{SD}=2.09\right), t(255)=$ $3.87, p<.001$, and when it was unspecified $\left(M_{\text {unint }}=3.77\right.$, $\mathrm{SD}=2.26$ vs. $\left.M_{\text {int }}=4.73, \mathrm{SD}=1.98\right), t(255)=3.63$, $p<.001$. On this measure we did observe a main effect of whether or not the focal attribute was specified, such that participants thought that the firm diverted fewer resources away from quality when the company intended to improve viscosity than when the focal benefit was unspecified, $F(1$, $510)=3.92, p=.048$. Importantly, however, there was no interaction with firm intentions $(p=.81)$

Product Quality. We did not observe any significant effect of intentions $(F(1,505)=1.23, p=.29)$ or interactions on the measures directly related to product quality $\left(M_{\text {unint }}=\right.$ $4.83, \mathrm{SD}=1.46$ vs. $M_{\text {int }}=4.86, \mathrm{SD}=1.62$, and $M_{\text {unint }+ \text { spec }}$ $=5.23, \mathrm{SD}=1.43$ vs. $\left.M_{\mathrm{int}+\mathrm{spec}}=4.91, \mathrm{SD}=1.51\right)$.

Mediation. We then conducted a bootstrap analysis with 5,000 samples (Preacher and Hayes 2008) to test whether the belief in resource allocation mediated the effect of firm intentions on purchase intent (whether or not the focal attribute specified and the interaction where included as covariates). Ratings of product quality were not included in this model, since we did not find differences on that measure. This analysis indicated that the indirect effect of resource allocation was significant $(a \times b=.086, \mathrm{SE}=.031 ; 95 \%$ $\mathrm{CI}=037$ to .158$)$.

\section{Discussion}

Results from experiment 2a indicated that explicitly stating that the company cares about both the environment and quality is not sufficient to overcome a decrease in purchase intent. In fact, results in the care-about-both condition followed the same pattern as those in the intended and control conditions. This result is consistent with our hypothesis that beliefs about resource allocation and notions of zero-sum are driving the effect of firm intentions on purchase intent.

The results from experiment $2 b$ helped to rule out a second potential alternative explanation, namely, that consumers inferred that if the firm unintentionally greened the product, it must have instead focused on improving quality. However, when we explicitly stated in all conditions that the company had focused on a specific performance attribute (improving viscosity), we still observed the predicted effects of intended (versus unintended) enhancements on inferences about resource allocation and subsequent purchase inten- 
tions. Thus, we replicate the findings of the previous studies even when information about the company's focus was specified.

\section{EXPERIMENT 3: BOUNDARY CONDITIONS}

The previous studies found support for the hypothesis that consumers are less likely to purchase green products if they believe that the green benefit is intended than when it occurs as an unintended side effect. However, other research on socially beneficial product attributes has identified a different pattern of results, often finding a positive halo effect on subsequent product evaluations (Nisbett and Wilson 1977). For example, past research has found that firms that engage in Corporate Social Responsibility (CSR) practices are perceived to have better products (Blair and Chernev 2014) and that fair trade chocolate is perceived to be healthier and lower in calories (Schuldt et al. 2012). The dominant mechanism in such cases is that the morally good benefit increases liking of the firm, which has a spillover effect on evaluations of the product. Though past research has not addressed the role of firm intentions per se, this research does raise important question regarding the contexts in which socially beneficial product enhancements lead to a decrease in consumer interest (as observed here) versus an increase in consumer interest.

We suggest that one key difference between these two types of findings is whether or not the socially beneficial attribute is integral to the composition of the product. For example, green benefits are typically inherent to the product itself and involve features of the product (e.g., increased biodegradability, less harmful chemicals). In contrast, benefits such as fair trade or CSR reflect actions of the firm and are separate from the product. Therefore, we hypothesize that one key difference between these two sets of findings - and, thus, a key moderator of the negative effect of firm intentions on purchase interest-may be whether or not the benefit in question is inherent to the product's composition.

The present study tested this prediction directly. We predicted that when consumers are told about a benefit that is inherent to the composition of the product (e.g., a green benefit), they will infer that the company diverted resources away from product quality and, as a result, will be less likely to purchase the product. However, when the enhancement is separate from the composition of the product, such as when a company engages in fair trade practices, consumers will not make compensatory inferences and will instead have positive evaluations of the product-perhaps even more positive when that benefit is perceived as intended (vs. unintended) — because positive feelings toward the firm may carry over to evaluations of the product.

Furthermore, combining the results of the previous three studies as well as the work on halo effects (Blair and Chernev 2014; Schuldt et al. 2012) we predict two different mechanisms underlying this interaction. In the case of in- tended (unintended) green benefits, the present studies identify a mechanism related to beliefs about resource allocation and subsequent expectations about quality. In contrast, research on halo effects has identified a mechanism related to liking of the firm. Therefore, the present study tests for moderated mediation whereby, for green benefits (inherent to the product), inferences about resource allocation and quality mediate the effect of firm intentions on purchase intent, while for fair trade benefits (separate from the product), liking of the firm mediates the effect of intended (vs. unintended) benefits on purchase intent.

\section{Method}

We recruited 400 adult participants $\left(M_{\text {age }}=29.7,34 \%\right.$ female) from Amazon's Mechanical Turk. Participants were randomly assigned to one of four conditions in a 2 intention (intended vs. unintended) $\times 2$ type of socially beneficial enhancement (inherent vs. separate) design. All participants evaluated an all-purpose cleaner. Participants in the inherent benefit conditions evaluated stimuli that were identical to the intended and unintended conditions of experiment 2a. Specifically, participants in the intended conditions read that "as initially intended, the all-purpose cleaner is better for the environment," whereas participants in the unintended conditions read that green benefit occurred as "an unintended side effect" (see app. D).

Participants in the separate benefit conditions read about the same manufacturer, but in these cases, the benefit was a fair trade agreement with the workers manufacturing the all-purpose cleaner. In the intended conditions participants read that, "as intended, the new trade agreement provides overseas workers with a fair wage and higher quality of life in their home country." In contrast, in the unintended conditions participants read that the local government now mandates a fair trade agreement. Therefore, "as an unintended consequence, the new trade agreement provides overseas workers with a fair wage and higher quality of life in their home country." After reading these vignettes, participants reported their purchase intent $(1=$ definitely would not buy, 9 = definitely would buy), perception of the product's cleaning ability $(1=$ low, $5=$ average, $9=$ high $)$, agreement with the resource allocation statement, and liking of the firm $(1=$ not at all, $9=$ very much $)$.

\section{Results}

Purchase Intent. Results from this study are depicted in figure 3. A two-way ANOVA revealed a significant interaction between the firm's intention (intended vs. unintended) and the type of socially beneficial enhancement (inherent vs. separate), $F(1,396)=14.58, p<.001$. As was observed in the previous studies, purchase intent was higher when the green (inherent) benefit was unintended compared to when it was intended $\left(M_{\text {unint }}=6.98, \mathrm{SD}=1.35\right.$ vs. $M_{\text {int }}=6.16$, $\mathrm{SD}=1.70), t(196)=3.75, p<.001$. However, when the benefit was separate from the product (fair trade), there was a marginal effect in the opposite direction, such that pur- 
FIGURE 3

MEAN RATINGS OF PURCHASE INTENT IN EXPERIMENT 3

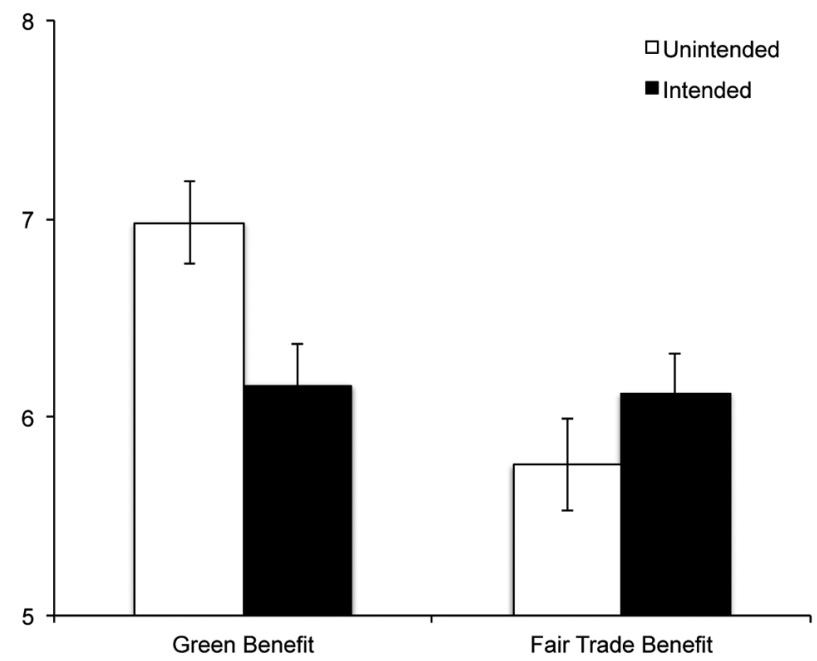

chase intent was higher when the fair trade contract was intended compared to when it was unintended $\left(M_{\text {int }}=6.12\right.$, $\mathrm{SD}=1.62$ vs. $\left.M_{\text {unint }}=5.76, \mathrm{SD}=1.44\right), t(200)=1.55$, $p=.10$.

Product Quality. Measures of product quality were submitted to an analogous two-way ANOVA, which revealed a significant interaction between the firm's intention and the type of social benefit, $F(1,396)=12.72, p<.001$. In the green (inherent) conditions, we again observed that participants reported higher product quality when the green benefit was unintended than when it was intended $\left(M_{\text {unint }}=6.69\right.$, $\mathrm{SD}=1.31$ vs. $\left.M_{\text {int }}=5.99, \mathrm{SD}=1.47\right), t(196)=3.55$, $p<.001$. However, when the benefit was separate from the product (fair trade), there was a trending effect in the opposite direction, such that participants reported higher product quality when the fair trade contract was intended than when it was unintended $\left(M_{\text {int }}=5.94, \mathrm{SD}=1.36\right.$ vs. $M_{\text {unint }}$ $=5.70, \mathrm{SD}=1.15), t(200)=1.38, p=.17$.

Resource Allocation. For the measure related to beliefs about resource allocation, the interaction between the firm's intentions and the type of social benefit was only marginally significant, $F(1,396)=2.12, p=.14$. Here, the pattern was somewhat different. In the green conditions, we observed that, as expected, participants believed that the company diverted more resources away from quality when the green benefit was intended than when it was unintended $\left(M_{\text {int }}=4.51, \mathrm{SD}=2.12\right.$ vs. $\left.M_{\text {unint }}=3.19, \mathrm{SD}=2.01\right)$, $t(196)=4.50, p<.001$. Unlike the other measures, however, in the case of the fair trade, participants also thought the company diverted more resources away from quality when it intentionally made the fair trade agreement, albeit to a lesser extent than in the green benefit conditions $\left(M_{\mathrm{int}}\right.$
$=3.73, \mathrm{SD}=1.99$ vs. $\left.M_{\text {unint }}=3.01, \mathrm{SD}=1.94\right), t(200)$ $=2.60, p=.01$.

Liking. Measures of liking also showed a marginal interaction between the firm's intention and the type of social benefit, $F(1,396)=2.96, p=.09$. Consistent with past research on halo effects, when the benefit was separate (fair trade), participants expressed greater liking of the firm when the benefit was intended than when it was unintended $\left(M_{\text {int }}\right.$ $=6.21, \mathrm{SD}=1.75$ vs. $\left.M_{\text {unint }}=5.43, \mathrm{SD}=1.93\right), t(200)$ $=2.99, p=.003$. In the case of the green benefit, however, there was no difference in liking of the firm depending on whether or not the firm intended to make the green enhancement $\left(M_{\text {int }}=6.44, \mathrm{SD}=1.73\right.$ vs. $M_{\text {unint }}=6.25, \mathrm{SD}$ $=1.39), t(196)=0.85, p=.39$.

Mediation. We then conducted a moderated mediation analysis to test the predicted relationship of firm intentions by type of social benefit on purchase intent through the mediators of quality ratings (green benefit) and liking (fair trade benefit). Firm intentions were entered as the predictor variable, benefit type (inherent versus separate) as the moderator, and quality ratings and liking were the two mediators. The bootstrap analysis indicated that the full model was significant, $R^{2}=.55, p<.0001$ (see fig. 4 ), and that there were two distinct indirect effects that were conditional on the benefit type. As predicted, inferences about quality mediated the effect of firm intentions on purchase intent for the green enhancement (inherent benefit) (indirect effect $=$ $-.43 ; 95 \% \mathrm{CI}=-.716$ to -.201$)$ but not for the fair trade contract (separate benefit) (indirect effect $=.15 ; 95 \% \mathrm{CI}=$ -.062 to .372). Conversely, liking of the firm mediated the effect of firm intentions on purchase intent for the fair trade contract (separate benefit; indirect effect $=.19 ; 95 \% \mathrm{CI}=$ .069 to .366) but not for the green enhancement (inherent benefit) (indirect effect $=.05 ; 95 \% \mathrm{CI}=-.059$ to .170 ).

We conducted one further serial mediation analysis that included inferences about resource allocation as well as quality (since a combined serial and moderation analysis was not permitted in the model above), which tested the same pathway as examined in the previous three studies. Again replicating the previous analyses, this analysis indicated that for the green enhancement (inherent benefit), the full serial mediation model using both quality and resource allocation was significant (indirect effect $=-.16$; 95\% CI $=-.33$ to -.05$)$. However, this same model was not significant for the fair trade benefit (indirect effect $=-.04$; $95 \% \mathrm{CI}=-.15$ to .01$)$.

\section{Discussion}

In sum, purchase intent and quality ratings showed the predicted patterns of results: when the benefit was inherent to the product (green benefit) unintended improvements were rated more favorably (higher quality and higher purchase intent) than intended improvements. Conversely, when the benefit was separate from the product (fair trade) intended improvements were rated more favorably than un- 
FIGURE 4

MODERATED MEDIATION ANALYSES (EXPERIMENT 3)

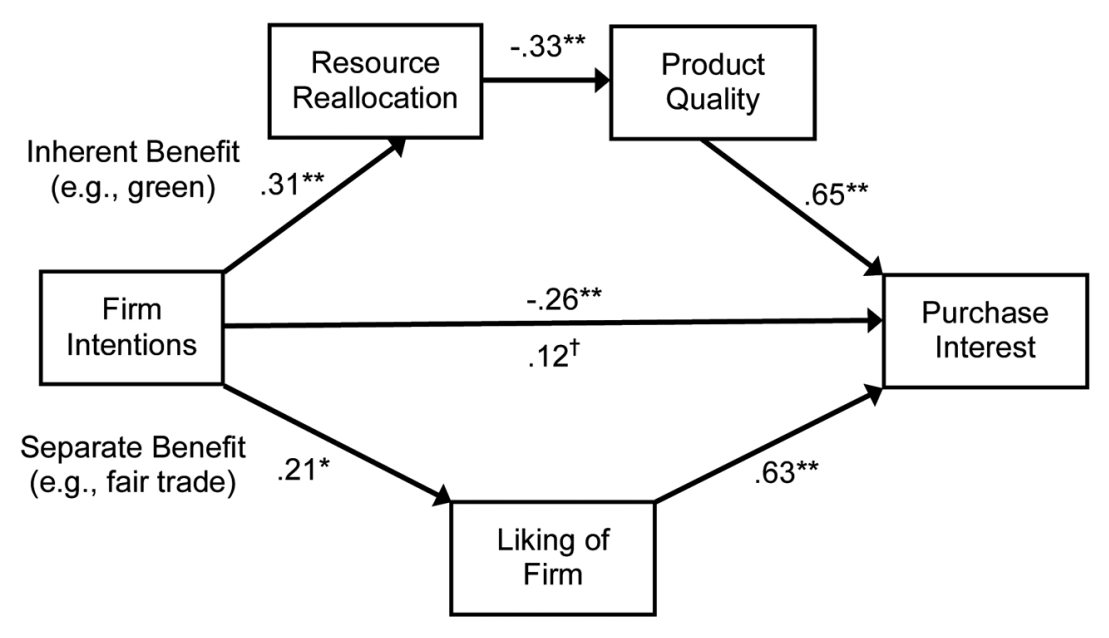

NOTE. $-{ }^{\dagger} p=.10,{ }^{*} p<.01,{ }^{*} p p<.001$

intended ones. Measures of resource allocation and liking of the firm showed somewhat different patterns, where, on the whole, intended (vs. unintended) benefits were seen as drawing more resources away from quality, but intended (vs. unintended) benefits also led to greater liking of the firm. However, this second set of conclusions (pertaining to measures of resources and liking) should be qualified by the fact that participants believed that the firm diverted resources away from quality more when the benefit was inherent to the product than when it was separate (Cohen's $d$ of .64 vs. .37 , respectively). In addition, the effect of liking was much greater when the benefit was separate from the product compared to when it was inherent (Cohen's $d$ of .42 vs. .12, respectively).

This difference between the inherent versus separate benefits was further specified by the results of the mediation analyses. We observed that the effect of firm intentions on purchase intent was mediated by inferences about quality when the benefit was inherent to the product (green benefit) but not when the benefit was separate from the product (fair trade). Conversely, the effect of firm intentions on purchase intent was mediated by liking of the firm when the benefit was separate from the product but not when the benefit was inherent to it. This result is highly informative as it both $(a)$ demonstrates an important boundary condition on the negative intention effect observed in the first two experiments and $(b)$ provides a way of reconciling the current effects with previous studies that have found a positive halo effect on product evaluations.

This study also identified at least two patterns of results that are potentially worthy of further research. The first is the implied dissociation between purchase interest and liking of the firm for green products. The results from this study suggest that, in essence, intended (vs. unintended) green improvements may lead individuals to express both lower purchase interest in the product (because of quality perceptions) but potentially greater liking of the firm. This may be an interesting pattern to investigate in subsequent research in order to identify the situations in which consumers may be more likely to weight quality inferences versus liking of the firm when purchasing products with social benefits. It further suggests that if firms are able to overcome or address inferences about lower product quality, they may be able to capitalize on positive reputational benefits.

The second interesting result that is that participants did seem to infer (at least some) reallocation of resources even when the benefit was separate from the product (i.e., fair trade). This suggests that inferences about zero-sum may be quite robust, extending beyond beliefs about product composition. At the same time, such inferences do not always appear to lead to beliefs about diminished quality. For example, it may be that in cases such as fair trade, the belief that the firm allocated fewer resources to quality is overcome by the halo effect associated with the greater liking of the firm.

\section{EXPERIMENT 4: ADDITIONAL ATTRIBUTE TRADE-OFFS}

The goal of experiment 4 was to explore the generality of the intended versus unintended effect. The previous studies all examined green enhancements for home goods (cleaners, dish soap, etc.). In this study we examined a new product category in order to test whether similar effects exist for 
other types of socially desirable trade-offs in product attributes. Specifically, we built on previous research which has identified a tasty $=$ unhealthy lay theory regarding food products (Raghunathan et al. 2006).

Participants read a mock news article about a new method of producing ice cream (which was actually low-temperature extrusion, or the "slow-churned" process). Half of the participants read that this new method was developed because manufacturers intended to create a new ice cream that was both tastier and healthier. The other half of participants read that the new method was developed because manufacturers intended to find a tastier ice cream and that health benefits occurred as an unintended side effect. In both cases, the ice cream and production methods were described identically - the only thing that differed was information regarding the intentions (or lack thereof) behind developing the ice cream's health benefits.

Based on the results of the previous experiments, we predicted that consumers should assume that resources are zerosum and, thus, infer that the ice cream that was intended to be healthier is less tasty than the ice cream that was healthier as an unintended side effect. Beyond extending the intended versus unintended effect into a new domain, this study also had a number of methodological benefits in that it relied on more naturalistic stimuli, provided identical information about the underlying process/innovation (low-temperature extrusion), and eliminated potential confounds (e.g., the number of enhancements) that the previous experiments sought to address. In addition, this study offered practical relevance as a number of large food and beverage companies, such as PepsiCo, have been experiencing pressure from the government to improve the healthfulness of their offerings and have started to reengineer some of their products to reduce their sugar, salt, and fat content.

\section{Method}

We recruited 295 adult participants $\left(M_{\text {age }}=36.8,61 \%\right.$ female) from an online survey pool. All participants were asked to read a fictitious newspaper article (based on an actual article; see Moskin 2006) about a new method for producing ice cream. Participants in both conditions (intended vs. unintended) read about a new low-temperature extrusion process for manufacturing ice cream. Participants in the intended conditions read that the ice cream industry developed this new method because they both "intended to create an ice cream that was much healthier," and "develop a product that matched the creaminess of homemade ice cream." In contrast, participants in the unintended condition read that ice cream industry developed this new method because they "intended to develop a product that matched the creaminess of homemade ice cream," and that unintentionally they "also happened to develop a product that was much healthier too" (see app. E).

After reading these vignettes, participants rated how tasty $(1=$ not tasty, $9=$ very tasty $)$, how rich tasting $(1=$ not rich, $9=$ very rich $)$, and how creamy $(1=$ not creamy, 9 $=$ very creamy) they thought the ice cream would be. They also rated their agreement with a statement regarding resource allocation ("Do you think that in order to make the ice cream healthier, the company took resources away from making this product better tasting?" $1=$ definitely not, 9 $=$ definitely) as well as their likelihood of purchase $(1=$ not at all likely, $9=$ very likely).

At the end of the study, participants were asked to complete a manipulation check in which they were asked to recall whether the health benefits of the ice cream were intended or unintended or whether they did not remember. A manipulation check was used in this study given the more naturalistic, and hence, subtle manipulation of firm intentions. Forty-eight participants (16\%) did not pass this check (selected either the incorrect option or reported that they did not remember) and were excluded from subsequent analyses.

\section{Results}

The measures related to tastiness/product quality formed a reliable scale $(\alpha=.86)$ and were averaged to produce a single measure. Consistent with the findings of the previous studies, participants thought that the ice cream would be tastier when the health benefit was unintended compared to when it was intended $\left(M_{\text {unint }}=7.11, \mathrm{SD}=1.22 \mathrm{vs} . M_{\mathrm{int}}=\right.$ $6.59, \mathrm{SD}=1.44), t(245)=3.03, p=.003$. Additionally, participants were less likely to agree that the manufacturers diverted resources away from product quality when the health benefit was unintended than when it was intended $\left(M_{\text {unint }}=4.33, \mathrm{SD}=2.17\right.$ vs. $\left.M_{\text {int }}=5.17, \mathrm{SD}=2.33\right)$, $t(243)=2.91, p=.004$. Measures of purchase intent were not significantly different across the intended versus unintended conditions, $t(244)=.75, p=.45$, though the pattern was directionally consistent with the previous studies, $\left(M_{\text {unint }}\right.$ $=6.22, \mathrm{SD}=2.11$ vs. $\left.M_{\mathrm{int}}=6.02, \mathrm{SD}=2.05\right)$.

\section{Mediation}

We then conducted a serial mediation analysis to test the predicted relationship between resource allocation, product quality, and purchase intent (analogous to the previous studies). A bootstrap analysis with 5,000 samples (Preacher and Hayes 2008) indicated that the full serial mediation model using both quality and resource allocation was significant (indirect effect $=-.22, \mathrm{SE}=.08,95 \% \mathrm{CI}=-.41$ to $-.08)$. However, additional analyses indicated that the "reverse" model (intentions $\rightarrow$ quality $\rightarrow$ resources $\rightarrow$ purchase intent) was much weaker (indirect effect $=-.069, \mathrm{SE}=$ $.04,95 \% \mathrm{CI}=-.17$ to -.02$)$, suggesting that the predicted serial mediation model best explained our data.

\section{Discussion}

These results indicate that the effects of intended (vs. unintended) enhancements extend beyond green products to include other types of trade-offs such as the link between the healthfulness of a product and taste. This study also contributed to the previous studies in that the stimuli relied on a more naturalistic context that was derived from an 
actual newspaper article. Finally, this study was novel in that it provided specific information about the underlying manufacturing process (i.e., low-temperature extrusion). This is important because it shows that the intended (vs. unintended) effect persists even when specific information about the product enhancement is provided.

\section{GENERAL DISCUSSION}

Beliefs about intentionality are central to many aspects of psychology. However, to date, little is known about how intentions may influence consumer perceptions. The present studies offer insight into this process as they suggest that information about the firm's intentions may play a key role in how socially beneficial products are evaluated. We observed that when a company makes an environmental enhancement to a product, consumers are less likely to purchase the product if they learn that the enhancement is intended, compared with when it occurs as an unintended side effect. This effect obtained across multiple types of products and scenarios. Thus, a principle finding of this paper is that intended improvements may have ironic consequences: deliberately enhancing a product to make it more appealing may actually lead to a decrease in consumer interest.

These studies also identify the underlying reasons for this effect while ruling out a number of alternative explanations. Experiment 1 established that differences in firm intentions lead consumers to draw different inferences about the allocation of the firm's resources. In turn, beliefs about resource allocation changed perceptions of product quality and ultimately, purchase intent. Moreover, this study established that in the absence of information about firm intentions, consumers appear to infer intentionality-in other words, intended enhancements appear to be the default assumption.

Experiments $2 \mathrm{a}$ and $2 \mathrm{~b}$ provided further support for the proposed mechanism by addressing potential alternative explanations. Specifically, experiment $2 \mathrm{a}$ showed that even when the company explicitly stated that they cared about both the environment and product quality, inferences about resource allocation and product quality were no different from the intended condition. Experiment $2 b$ further showed that even when it was explicitly stated that the company had focused on a nongreen attribute (improving viscosity), we still observed the predicted effect of intended (unintended) enhancements on inferences about resource allocation, suggesting that these results are not due to pragmatic inferences about areas of specialization.

Experiment 3 identified an important boundary condition. In this study we found that a key moderator of the negative effect of firm intentions on purchase intent is whether or not the benefit in question is inherent to the product's composition. A moderated mediation analysis indicated that when the benefit is inherent to the composition of the product (e.g., a green benefit), intended (vs. unintended) benefits decrease purchase intent because of inferences about resource allocation and quality. However, when the benefit is separate from the product (e.g., fair trade), intended (vs. unintended) benefits increase purchase intentions because of liking of the firm.

Finally, experiment 4 demonstrated the robustness of this effect and found that the negative effect of firm intentions generalizes even to domains that are unrelated to green products. This result is important because it suggests that the intended (vs. unintended) effect may be much broader in scope and may extend to many contexts in which consumers have an intuitive theory that product enhancements along one dimension come at the expense of performance on other dimensions.

\section{Limitations and Future Directions}

Across studies, the effects of intentions on quality ratings were somewhat weaker than on the other measures (i.e., the measures of purchase intent and resource allocation). We found robust differences in experiments 1,3 , and 4 but somewhat weaker effect in experiment $2 \mathrm{a}$ and a null effect in experiment $2 \mathrm{~b}$. We suggest that the most likely explanation for this difference is related to the types of measures that were used. While the measures of purchase intent and beliefs about resource allocation were fairly straightforward (and generalize across product categories), the measures of quality asked about attributes that were specific to the product in question (e.g., a drain cleaner's ability to break up clogs). We argue that specific measures of quality are important given the potential practical implications of this research as well as the precedent set by previous research on the zero-sum heuristic, which also asked about specific quality attributes (e.g., Chernev 2007). Nevertheless, it is unlikely that participants have detailed theories about exactly how resource allocation changes specific quality attributes; rather, they may hold more general beliefs that the product is simply "worse." As a result, measures that ask about specific product attributes may produce weaker effects.

That said, the data as a whole suggest a very robust pattern of results that includes inferences about product quality. We find significant differences on the quality measures and significant mediation results in all but one study and, therefore, argue that the effect of firm intentions on purchase intent is in fact due to beliefs about how the firm allocated resources and subsequent inferences about product quality. This interpretation is further reinforced by the results of experiment 3 , which demonstrate that, when the social benefit is separate from the product itself, a very different sort of process model obtains, having to do with liking of the firm rather than inferences about product quality.

A second question involves other types of boundary conditions, such as individual differences in interest in green products. One might expect that desires to see green products in either a positive or negative light may in turn either reduce or enhance the negative impact of intended green enhancements on evaluations of green products (Jain and Maheswaran 2000). A series of pilot studies confirmed this prediction. For example, we conducted one experiment in which participants evaluated a series of green products adapted from Chernev (2007). Half of the participants read that the 
green enhancement was intended, while the other half read that the green enhancement was unintended. Participants then rated the perceived quality of the products, and also completed a 10-item scale, which assessed participants' concern for the environment and their interest in green products overall $(\alpha=.85)$.

The results from this experiment indicated a significant two-way interaction between the firm's intentions and greeninterest, $\beta=-.16, p<.05$. A further spotlight analysis at plus and minus one standard indicated that individuals low in green interest judged the perceived quality of the products to be worse when the green improvement was intended versus when it was unintended, $\beta=.29, p=.014$. In contrast, for participants that were higher in green interest, the manipulation of intention had no effect on ratings of perceived product quality, $\beta=-.04, p=.72$

These initial results suggest yet another interesting avenue for future research in this area. In particular, it appears that motivated reasoning (Jain and Maheswaran 2000) can lead individuals to override the zero-sum heuristic and see green products in a positive light. This raises a number of interesting questions regarding how inferences about firm resources may interact with motivated reasoning. For example, do these processes interact serially such that positivity toward green products literally overrides the zero-sum heuristic? Would changes in the degree of deliberation (e.g., via manipulations of cognitive load or response time) make high-green-interest consumers respond more like low-greeninterest consumers? What other types of motivations might override inferences related to the zero-sum heuristic and firm intentions? We see these as interesting areas for future investigation in this area.

\section{Implications}

These results have a number of theoretical and practical implications. Beyond broadly demonstrating the importance of firm intentions to consumer perceptions, one theoretical contribution of this work is that it sheds light on intentions as an important moderator of consumer's reliance on the zero-sum heuristic. While prior research has focused on documenting the existence of compensatory inferences in different contexts (see, e.g., across alternatives, Chernev and Carpenter 2001; or, within an alternative, Chernev 2007), little research has been done to identify factors that are likely to foster or attenuate them. In this context, our research demonstrates that consumers are more likely to make compensatory inferences when they perceive that the company intentionally invested resources in one particular attribute or diverted them away from other attributes, which in turn appears to have important downstream consequences for purchase intentions.

A second significant theoretical contribution of this work is that it identifies the conditions under which socially beneficial actions will either increase or decrease consumer interest. In short, there are two main theoretical models that make contrasting predictions about the evaluation of product enhancements: compensation or zero-sum (discussed above) and covariation. Under a covariation model (e.g., Bettman, John, and Scott 1986), individuals may assume that positive attributes on one dimension correspond to improvements on other dimensions (i.e., halo effects). In this vein, our research serves to link these two models by demonstrating that within the domain of socially beneficial product attributes, a key factor seems to be whether the benefit is seen as inherent to the product itself or separate. This finding may be worthy of further investigation. Future research could illuminate the specific boundary conditions around the types of benefits that are likely to be seen as part of the product or not, as well as the potential changes in the evaluative context (e.g., consumer mind-set) that may push individuals toward one construal or another.

From an applied perspective, these results are relevant to a number of firms that offer products with environmental benefits. Several surveys of consumer attitudes have identified that one of the most important issues for consumers when deciding whether or not to purchase green products is whether the quality of the green product is undermined (Ginsberg and Bloom 2004; Roper Green Gauge Report 2002). Therefore, these findings may be particularly relevant, as they suggest a number of ways that firms manufacturing green products may best communicate those environmental benefits, while avoiding any potential losses in consumer interest.

The results of experiment 3 suggest a second practical implication. Where applicable, firms may benefit from distancing socially beneficial enhancements from the product itself, thereby obviating losses in perceived quality while maintaining a boost in reputation. In cases where the benefit is inherent to the product, the present studies suggest that firms may need to go the extra mile in specifying the exact nature of the enhancement and how it came about and in ensuring that consumers better understand the underlying mechanisms supporting both the product's green benefits and its quality on other dimensions.

\section{CONCLUSION}

The present studies provide one of the first investigations into the effect of intentions on consumer perceptions. These results are informative because they identify that (1) intentions are central to the application of different lay beliefs regarding how firms allocate their resources, (2) the effects of socially beneficial product enhancements can be counterintuitive, in that intending to improve a product may backfire and can actually make consumers less likely to purchase it, and (3) a key moderator of compensatory inferences versus halo effects appears to be whether the social benefit is seen as something that is part of the product or not. From an applied perspective, these results are also informative as they not only shed light on how green products are evaluated by consumers but also suggest a number of ways that companies interested in manufacturing green products may best communicate those efforts. 


\section{DATA COLLECTION INFORMATION}

The second author collected data for studies 1, 2a, and 3 using Qualtrics software and Amazon's Mechanical Turk online platform in June 2012, August 2012, and April 2013, respectively. Research assistants under the supervision of the university's lab manager collected data for study $2 \mathrm{~b}$ in July 2012 on the Charles River Esplanade in Boston during a Fourth of July celebration. The second author collected data for study 4 using Qualtrics and the university's online survey panel in January 2014. The first and second author both independently analyzed the data for studies $1,2 \mathrm{a}, 2 \mathrm{~b}$, 3 , and 4 .

\section{APPENDIX A EXPERIMENT 1 STIMULI}

\section{Control Condition}

The Keyes Corporation manufactures household cleaning products such as detergents and cleaning sprays. In a meeting with the CEO of the Keyes Corporation, the Vice President of R\&D, Joe Smith, announces that the R\&D team has been working for months on developing a new formula for dishwashing soap. Extensive tests have revealed that the new formula is better for the environment.

Joe Smith states, "This new dishwashing soap is significantly better for the environment than competing brands." Tests conducted by independent agencies confirm that the new dish soap is indeed better for the environment than any other brand in the marketplace.

\section{Intended Condition}

The Keyes Corporation manufactures household cleaning products such as detergents and cleaning sprays. In a meeting with the CEO of the Keyes Corporation, the Vice President of $R \& D$, Joe Smith, announces that the R\&D team has been working for months on developing a new formula for dishwashing soap that would be better for the environment. Extensive tests have revealed that the new formula is better for the environment.

Joe Smith states, "As we initially intended, this new dishwashing soap is significantly better for the environment than competing brands." Tests conducted by independent agencies confirm that the new dish soap is indeed better for the environment than any other brand in the marketplace.

\section{Unintended Condition}

The Keyes Corporation manufactures household cleaning products such as detergents and cleaning sprays. In a meeting with the CEO of the Keyes Corporation, the Vice President of R\&D, Joe Smith, announces that the R\&D team has been working for months on developing a new formula for dishwashing soap. Extensive tests have revealed that the new formula unexpectedly happens to be better for the environment.

Joe Smith states, "As an unintended side effect, this new dishwashing soap is significantly better for the environment than competing brands." Tests conducted by independent agencies confirm that the new dish soap is indeed better for the environment than any other brand in the marketplace.

\section{APPENDIX B EXPERIMENT 2A STIMULI}

\section{Control Condition}

The Keyes Corporation manufactures household cleaning products such as detergents and cleaning sprays. In a meeting with the CEO of the Keyes Corporation, the Vice President of Research and Development, Joe Smith, announces that the Research team has been working for months on developing a new formula for an all-purpose household cleaner. Extensive tests have revealed that the new formula is better for the environment.

Joe Smith states, "This new household cleaner is significantly better for the environment than competing brands." Tests conducted by independent agencies confirm that the new household cleaner is indeed better for the environment than any other brand in the marketplace.

\section{Intended Condition}

The Keyes Corporation manufactures household cleaning products such as detergents and cleaning sprays. In a meeting with the CEO of the Keyes Corporation, the Vice President of Research and Development, Joe Smith, announces that the Research team has been working for months on developing a new formula for an all-purpose household cleaner that is better for the environment. Extensive tests have revealed that the new formula is better for the environment.

Joe Smith states, "As we initially intended, this new household cleaner is significantly better for the environment than competing brands." Tests conducted by independent agencies confirm that the new household cleaner is indeed better for the environment than any other brand in the marketplace.

\section{Unintended Condition}

The Keyes Corporation manufactures household cleaning products such as detergents and cleaning sprays. In a meeting with the CEO of the Keyes Corporation, the Vice President of Research and Development, Joe Smith, announces that the Research team has been working for months on developing a new formula for an all-purpose household cleaner. Extensive tests have revealed that the new formula unexpectedly happens to be better for the environment.

Joe Smith states, "As an unintended side effect, this new household cleaner is significantly better for the environment 
than competing brands." Tests conducted by independent agencies confirm that the new household cleaner is indeed better for the environment than any other brand in the marketplace.

\section{Care-about-Both Condition}

The Keyes Corporation manufactures household cleaning products such as detergents and cleaning sprays. In a meeting with the CEO of the Keyes Corporation, the Vice President of Research and Development, Joe Smith, announces that the Research team has been working for months on developing a new formula for an all-purpose household cleaner that is both better for the environment and is a good household cleaner. Extensive tests have revealed that the new formula is better for the environment.

Joe Smith states, "As we initially intended, this new household cleaner is significantly better for the environment than competing brands." Tests conducted by independent agencies confirm that the new household cleaner is indeed better for the environment than any other brand in the marketplace.

\section{APPENDIX C EXPERIMENT 2B STIMULI}

\section{Intended, Focal Attribute Unspecified Condition}

The Keyes Corporation manufactures household cleaning products such as detergents and cleaning sprays. In a meeting with the CEO of the Keyes Corporation, the Vice President of Research and Development, Joe Smith, announces that the Research team has been working for months on developing a new formula for drain cleaner (drain declogging solution) that would be better for the environment. Extensive tests have revealed that the new formula is better for the environment.

Joe Smith states, "As we initially intended, this new drain cleaner is significantly better for the environment than competing brands." Tests conducted by independent agencies confirm that the new drain cleaner is indeed better for the environment than any other brand in the marketplace.

\section{Unintended, Focal Attribute Unspecified Condition}

The Keyes Corporation manufactures household cleaning products such as detergents and cleaning sprays. In a meeting with the CEO of the Keyes Corporation, the Vice President of Research and Development, Joe Smith, announces that the Research team has been working for months on developing a new formula for drain cleaner (drain declogging solution). Extensive tests have revealed that the new formula unexpectedly happens to be better for the environment.

Joe Smith states, "As an unintended consequence, this new drain cleaner is significantly better for the environment than competing brands." Tests conducted by independent agencies confirm that the new drain cleaner is indeed better for the environment than any other brand in the marketplace.

\section{Intended, Focal Attribute Specified Condition}

The Keyes Corporation manufactures household cleaning products such as detergents and cleaning sprays. In a meeting with the CEO of the Keyes Corporation, the Vice President of Research and Development, Joe Smith, announces that the Research team has been working for months on developing a new formula for drain cleaner (drain declogging solution) that would both have better viscosity and be better for the environment. Extensive tests have revealed that the new formula does have better viscosity and is better for the environment.

Joe Smith states, "As we initially intended, this new drain cleaner is significantly better for the environment than competing brands." Tests conducted by independent agencies confirm that the new drain cleaner is indeed better for the environment than any other brand in the marketplace.

\section{Unintended, Focal Attribute Specified Condition}

The Keyes Corporation manufactures household cleaning products such as detergents and cleaning sprays. In a meeting with the CEO of the Keyes Corporation, the Vice President of Research and Development, Joe Smith, announces that the Research team has been working for months on developing a new formula for drain cleaner (drain declogging solution) that would have better viscosity. Extensive tests have revealed that the new formula does have better viscosity and unexpectedly also happens to be better for the environment.

Joe Smith states, "As an unintended consequence, this new drain cleaner is significantly better for the environment than competing brands." Tests conducted by independent agencies confirm that the new drain cleaner is indeed better for the environment than any other brand in the marketplace.

\section{APPENDIX D EXPERIMENT 3 STIMULI}

\section{Intended, Integral Condition}

The Keyes Corporation manufactures household cleaning products such as detergents and cleaning sprays. In a meeting with the CEO of the Keyes Corporation, the Vice President of R\&D, Joe Smith, announces that the research team has been working for months on developing a new formula for an all-purpose cleaner that would be better for the environment. Extensive tests have revealed that the new formula is better for the environment.

Joe Smith states, "As we initially intended, this new allpurpose cleaner is significantly better for the environment compared to products offered by competing brands." Tests conducted by independent agencies confirm that the new 
all-purpose cleaner is indeed better for the environment than any other brand in the marketplace.

\section{Unintended, Integral Condition}

The Keyes Corporation manufactures household cleaning products such as detergents and cleaning sprays. In a meeting with the CEO of the Keyes Corporation, the Vice President of R\&D, Joe Smith, announces that the research team has been working for months on developing a new formula for all-purpose cleaner. Extensive tests have revealed that the new formula unexpectedly happens to be better for the environment.

Joe Smith states, "As an unintended side effect, this new all-purpose cleaner is significantly better for the environment compared to products offered by competing brands." Tests conducted by independent agencies confirm that the new all-purpose cleaner is indeed better for the environment than any other brand in the marketplace.

\section{Intended, Separate Condition}

The Keyes Corporation manufactures household cleaning products such as detergents and cleaning sprays. In a meeting with the CEO of the Keyes Corporation, the Vice President of Human Resources, Joe Smith, announces that the HR team has been working for months on developing a new "fair trade" contract in its overseas factory, which manu- factures its all-purpose cleaner. The new contract provides its foreign workers with a higher quality of life.

Joe Smith states, "As we intended, the new trade agreement provides overseas workers with a fair wage and higher quality of life in their home country." Tests conducted by independent agencies indicate that this new contract is indeed better for the employees compared to companies who employ workers in similar factory jobs in the same country.

\section{Unintended, Separate Condition}

The Keyes Corporation manufactures household cleaning products such as detergents and cleaning sprays. In a meeting with the CEO of the Keyes Corporation, the Vice President of Human Resources, Joe Smith, announces that the HR team has been working on negotiating a new contract in its overseas factory, which manufactures its all-purpose cleaner. The local government now mandates a "fair trade" agreement. Therefore, while the Keyes Corporation did not intend to employ workers under the fair trade agreement, the new contract does have the benefit of proving its foreign workers with a higher quality of life.

Joe Smith states, "As an unintended consequence, the new trade agreement provides overseas workers with a fair wage and higher quality of life in their home country." Tests conducted by independent agencies indicate that this new contract is indeed better for the employees compared to companies who employ workers in similar factory jobs in the same country.

\section{APPENDIX E}

\section{FIGURE E1}

\section{Ëbe Arew Hork Eimes}

\author{
Searching for
better tasting \\ THE ice cream industry has been on a \\ quest to create ice cream that is much \\ healthier for consumers and is better \\ tasting. Through a new process called \\ low-temperature extrusion, ice cream \\ manufactures have been able to offer \\ an ice cream that many say raises the \\ "healthiness" bar for the ice cream \\ industry.
}

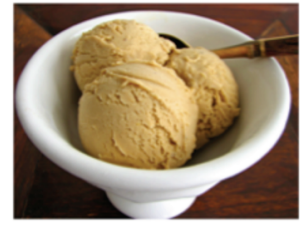

As another intended benefit of this new manufacturing process, these new ice creams are also much creamier-they are better in texture, and much better tasting. As one industry expert put it, "We originally intended to create an ice cream that was much healthier. We also intended to develop a product that matched the creaminess of homemade ice cream."

\section{The Alew Hork Eimes}

\author{
Searching for a better tasting ice cream, but \\ discovering a healthier option
}

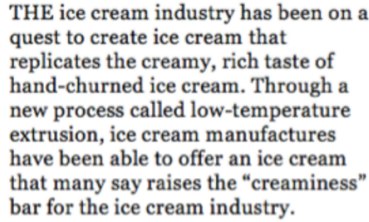

THE ice cream industry has been on a quest to create ice cream that replicates the creamy, rich taste of hand-churned ice cream. Through a new process called low-temperature extrusion, ice cream manufactures have been able to offer an ice cream that many say raises the "creaminess" bar for the ice cream industry.

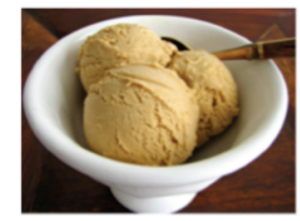

As an added bonus of this new manufacturing process, these new ice creams are also healthier-they contain half the fat, and two-thirds the calories of traditional ice creams. As one industry expert put it, "We originally intended to create an ice cream that matched the creaminess of homemade ice cream. Unintentionally, we also happened to develop a product that was much healthier too." 


\section{REFERENCES}

Bettman, James R., Deborah Roedder John, and Carol A. Scott (1986), "Covariation Assessment by Consumers," Journal of Consumer Research, 13 (December), 316-26.

Blair, Sean, and Alexander Chernev (2014), "Doing Well by Doing Good: The Benevolent Halo of Social Goodwill," Working paper, Kellogg School of Management, Northwestern University.

Brown, Tom J., and Peter A. Dacin (1997), "The Company and the Product: Corporate Associations and Consumer Product Responses," Journal of Marketing, 61 (January), 68-84.

Caruana, Robert (2007), "A Sociological Perspective of Consumption Morality," Journal of Consumer Behaviour, 6 (5), 287-304.

Chernev, Alexander, and Gregory S. Carpenter (2001), "The Role of Market Efficiency Intuitions in Consumer Choice: A Case of Compensatory Inferences," Journal of Marketing Research, 38 (August), 349-61.

- (2007), "Jack of All Trades or Master of One? Product Differentiation and Compensatory Reasoning in Consumer Choice," Journal of Consumer Research, 33 (March), 43044.

Creyer, Elizabeth H. (1997), "The Influence of Firm Behavior on Purchase Intention: Do Consumers Really Care about Business Ethics?," Journal of Consumer Marketing, 14 (6), 421-32.

Cushman, Fiery, and Alfred Mele (2008), "Intentional Action: Two-and-a-Half Folk Concepts?" in Experimental Philosophy, Vol. 2, ed. Joshua Knobe and Shaun Nichols, New York: Oxford University Press, 171-88.

Dik, Giel, and Henk Aarts (2007), "Behavioral Cues to Others' Motivation and Goal Pursuits: The Perception of Effort Facilitates Goal Inference and Contagion," Journal of Experimental Social Psychology, 43 (5), 727-37.

Ginsberg, Jill Meredith, and Paul N. Bloom (2004), "Choosing the Right Green Marketing Strategy," MIT Sloan Management Review, 46 (October), 79-84.

Heider, Fritz (1958), The Psychology of Interpersonal Relations, New York: Wiley.

Hunt, Nigel, and Brad Dorfman (2009), "How Green Is My Wallet? Organic Food Growth Slows," http://www.reuters.com.

Irwin, Julie R., and Jonathan Baron (2001), "Response Mode Effects and Moral Values," Organizational Behavior and Human Decision Processes, 84 (2), 177-97.

Jain, Shailendra P., and Durairaj Maheswaran (2000), "Motivated Reasoning: A Depth-of-Processing Perspective," Journal of Consumer Research, 26 (March), 358-71.

Knobe, Joshua (2003a), "Intentional Action and Side Effects in Ordinary Language," Analysis, 63 (279), 190-94.

- (2003b), "Intentional Action in Folk Psychology: An Experimental Investigation," Philosophical Psychology, 16 (2), 309-24.

Kruger, Justin, Derrick Wirtz, Leaf Van Boven, and T. William
Altermatt (2004), “The Effort Heuristic," Journal of Experimental Social Psychology, 40 (1), 91-98.

Leslie, Alan M., Joshua Knobe, and Adam Cohen (2006), “Acting Intentionally and the Side-Effect Effect Theory of Mind and Moral Judgment," Psychological Science, 17 (5), 421-27.

Lombrozo, Tania (2010), "Causal-Explanatory Pluralism: How Intentions, Functions, and Mechanisms Influence Causal Ascriptions," Cognitive Psychology, 61 (4), 303-32.

Morales, Andrea C. (2005), "Giving Firms an 'E' for Effort: Consumer Responses to High-Effort Firms," Journal of Consumer Research, 31 (4), 806-12.

Moskin, Julia (2006), "Creamy, Healthier Ice Cream? What's the Catch?" New York Times, July 26, http://www.nytimes.com/ 2006/07/26/dining $/ 26 \mathrm{cream}$. html ?pagewanted $=$ all\&_r $=0$.

Mukherjee, Ashesh, and Wayne D. Hoyer (2001), "The Effect of Novel Attributes on Product Evaluation," Journal of Consumer Research, 28 (December), 462-72.

Nisbett, Richard E., and Timothy D. Wilson (1977), "The Halo Effect: Evidence for Unconscious Alteration of Judgments," Journal of Personality and Social Psychology, 35 (4), 25056.

Nowlis, Stephen M., and Itamar Simonson (1996), "The Effect of New Product Features on Brand Choice," Journal of Marketing Research, 33 (February), 36-46.

Pizarro, David, Eric Uhlmann, and Peter Salovey (2003), “Asymmetry in Judgments of Moral Blame and Praise the Role of Perceived Metadesires," Psychological Science, 14 (3), 267-72.

Preacher, Kristopher J., and Andrew F. Hayes (2008), “Asymptotic and Resampling Strategies for Assessing and Comparing Indirect Effects in Multiple Mediator Models," Behavior Research Methods, 40 (3), 879-91.

Rajagopal, Raghunathan, Rebecca Walker Naylor, and Wayne D. Hoyer (2006), "The Unhealthy = Tasty Intuition and Its Effects on Taste Inferences, Enjoyment and Choice of Food Products," Journal of Marketing, 70 (4), 170-84.

Roper ASW (2002), “Green Gauge Report 2002," Roper ASW, New York.

Schuldt, Jonathon P., Dominique Muller, and Norbert Schwarz (2012), "The 'Fair Trade' Effect: Health Halos from Social Ethics Claims," Social Psychological and Personality Science, 3 (5), 581-89.

Sen, Sankar, and Chitra Bhanu Bhattacharya (2001), "Does Doing Good Always Lead to Doing Better? Consumer Reactions to Corporate Social Responsibility," Journal of Marketing Research, 38 (May), 225-43.

Thompson, Debora Viana, Rebecca W. Hamilton, and Roland T. Rust (2005), "Feature Fatigue: When Product Capabilities Become Too Much of a Good Thing," Journal of Marketing Research, 42 (4), 431-42.

Young, Liane, Fiery Cushman, Ralph Adolphs, Daniel Tranel, and Marc Hauser (2006), "Does Emotion Mediate the Effect of an Action's Moral Status on Its Intentional Status? Neuropsychological Evidence," Journal of Cognition and Culture, 6 (1-2), 291-304. 
Copyright of Journal of Consumer Research is the property of Journal of Consumer Research, Inc. and its content may not be copied or emailed to multiple sites or posted to a listserv without the copyright holder's express written permission. However, users may print, download, or email articles for individual use. 